\title{
A BUSCA PELOS ASPECTOS UNIVERSAIS DA MODA-DE-VIOLA
}

\author{
Jean Carlo Faustino \\ King's College, Londres \\ ieancarlofaustino@gmail.com
}

\begin{abstract}
Resumo
objetivo deste artigo é o de apresentar o histórico de uma busca pelos aspectos universais da moda-de-viola, a qual coincide com a realização de uma pesquisa de pós-doutoramento relacionada especificamente com este tema. Esta pesquisa, que foi realizada entre julho de 2015 e julho de 2016, tinha o objetivo inicial de compreender os aspectos universais da moda-de-viola através da análise das narrativas literárias de suas letras. No entanto, à medida que a pesquisa foi se desenvolvendo, o enfoque deixou de ser as narrativas das letras e converteu-se numa reflexão sobre a estrutura geral da sua forma musical, isto é, daqueles elementos musicais que normalmente são considerados pelos seus compositores para se obter legitimidade junto ao seu público ouvinte. A pesquisa em questão, no entanto, não ignora os aspectos regionais e mesmo históricos deste gênero musical. Pelo contrário, foi justamente a compreensão desses aspectos regionais, analisados ao longo de uma pesquisa de doutorado concluída em 2014, que suscitou esta reflexão complementar que aqui se apresenta.
\end{abstract}

Palavras-chave: universais; forma musical; Moda-de-viola; sociologia; música caipira. 


\begin{abstract}
The purpose of this article is to carry out the history of a search about the universal social aspects of moda-de-viola, which coincides with the completion of a post-doctoral research focused on this subject. This research, which was conducted between July 2015 and July 2016, had the initial goal of understanding the universal aspects of moda-de-viola through the analysis of the narratives of their lyrics. However, during the development of the research, the focus has move, from the narratives of lyrics, to a hypothetic general structure of its musical form, that is, those musical elements that are usually considered by their composers in the process of composition a song with legitimacy to the listening public of the twentieth century. The research in question, however, does not ignore the regional and even historical aspects of this musical genre. On the contrary, it was precisely the understanding of these regional aspects, analyzed in a doctoral research completed in 2014 , which has raised the further reflection that will be show here.
\end{abstract}

Keywords: universal; musical form; moda-de-viola; sociology; música caipira.

\title{
Lista de figuras
}

Figura 1: elementos obrigatórios das modas-de-viola

Figura 2: elementos obrigatórios e opcionais das modas-de-viola

Figura 3: distribuição demográfica da população brasileira

Figura 4: modelo estrutural revisado da moda-de-viola

Todas da minha própria autoria: Jean Carlo Faustino.

\section{5}




\section{Introdução}

"O êxodo cantado: a formação do caipira para a modernidade". Este foi o título da tese de doutorado em sociologia que realizei na Universidade Federal de São Carlos (UFSCar). O objetivo principal da tese foi o de revisitar o êxodo rural no estado de São Paulo através da análise das narrativas das modas-de-viola que foram gravadas na época. E a hipótese era a de que, nas histórias dessas narrativas, encontrava-se o registro das tensões e dos dilemas vividos pela população de origem camponesa diante do imperativo de se adaptar à cultura e economia do meio urbano $e$, consequentemente, à modernidade.

Em abril de 2014 a tese foi "defendida", como se costuma dizer, e aprovada no departamento de sociologia da UFSCar. Tratavase, portanto, de uma análise essencialmente sociológica que mostrava como era possivel reconstruir a história do exodo rural brasileiro sob a perspectiva dos vencidos (BENJAMIN, 1994, p. 225) e que destacava o que havia de nacional e regional nas narrativas das letras dessas modas-de-viola - no caso: naquelas que foram gravadas pela dupla Tião Carreiro e Pardinho, entre as décadas de 1960 e 1980.

No entanto, durante o trabalho de análise das narrativas foi possivel perceber como que as histórias que eram contadas não falavam apenas da realidade do camponês que estava migrando para as cidades ou já residindo nelas. Não raro, havia uma pretensão literária de formação humanista que mobilizava diferentes valores morais mesclando-os com a ética econômica própria da modernidade. E foi assim que surgiu a ideia de revisitar o mesmo objeto de estudo com o objetivo de compreender e explicar não mais o que ele revelava sobre um contexto histórico e social específico. Em vez disso, o novo objetivo agora seria o de estudar o oposto do que havia sido revelado na minha tese de doutorado destacando o que havia de universal nas narrativas dessas modas-de-viola.

Assim, após defender a tese de doutorado em abril de 2014, no final do mesmo ano eu apresentei uma proposta de trabalho no Kings College de Londres com o título " $\bigcirc$ Avesso da Tese: a busca pelos universais das modas de viola" - ou "Inside Out of Thesis: the search for the universals of moda-de-viola", em inglês. A proposta foi aceita em abril de 2015 e, em julho, eu a apresentei pessoalmente para o grupo de pesquisadores do Kings.

\section{6}


O objetivo deste artigo é, portanto, o de relatar esta experiência de pesquisa porque sua trajetória, desde a concepção do projeto até a conclusão do período de pesquisador visitante um ano depois, corresponde à história de uma busca pela compreensão e explicação dos aspectos universais deste gênero musical que é "tão nosso", isto é, tão brasileiro e tão datado historicamente e geograficamente tendo, simultaneamente, um potencial a ser desvendado e que a conectaria a outras culturas também.

\section{Uma coisa puxa outra}

Quando cheguei em Londres em julho de 2015 para apresentar presencialmente meu projeto para o grupo de pesquisadores reunidos no Department of Spanish, Portuguese and Latin American Studies do Kings College, o título do meu projeto de pesquisa foi alterado pelo meu coordenador: de "Inside Out of Thesis: the search for the universals of moda-de-viola" para "The search for universal themes and elements in the Brazilian musical genre of the moda-de-viola (rural guitar-based ballad)".

E a razão para esta mudança estava diretamente relacionada com uma lição que eu já havia aprendido (mas, ainda não internalizado) durante a disciplina obrigatória de metodologia no doutorado: ainda que uma nova pesquisa tenha o mesmo tema de uma pesquisa anterior, elas devem ser tratadas separadamente. Assim, mesmo que eu fosse trabalhar, na nova condição de pesquisador visitante, com o mesmo objeto de pesquisa do doutorado (as modas-de-viola gravadas pela dupla Tião Carreiro e Pardinho) e mesmo que o objetivo da pesquisa fosse complementar a anterior perspectiva, isto não faria muito sentido para aquele grupo de pesquisadores e a avaliação que eles iriam fazer da minha proposta naquela tarde. A alteração no título, no entanto, manteve o que era essencial: a busca pelos aspectos universais na moda-de-viola.

A principal premissa desta busca pelos aspectos universais e, consequentemente, do meu projeto de pesquisa era a de que haveria alguns elementos nas narrativas das modas-de-viola que teriam o potencial de tocar o espírito, por assim dizer, de um público que não era mais aquele para o qual essas composições foram feitas. No entanto, a forma como pretendia medir isto não era através de uma pesquisa empírica.

\section{7}


Inicialmente, eu pretendia estabelecer vínculos e pontes entre as narrativas das letras das modas-de-viola de Tião Carreiro e Pardinho com a obra de Shakespeare - um dos autores mais universais da modernidade e também do país que estava me recebendo como pesquisador. A expectativa era que este tipo de "literatura comparada" pudesse aproximar o público britânico, potencialmente familiarizado com as peças de teatro de Shakespeare, com o conteúdo das narrativas das modas-de-viola que, apesar da sua regionalidade, teria valores e virtudes humanas e humanísticas comuns.

Quando eu apresentei o projeto de pesquisa, houve uma espécie de polarização nas opiniões do grupo de pesquisadores do Kings: uma parte do grupo julgou a proposta como interessante e válida, enquanto que outra parte achava que uma comparação assim acabaria por ocultar as especificidades da moda-de-viola e o que ela tem, portanto, de mais interessante e único.

De fato, uma "literatura comparada" entre a moda-de-viola e Shakespeare acabaria por destacar apenas o aspecto literário da moda-de-viola acabando por relegar ao esquecimento sua musicalidade E foi assim, portanto, que decidi dar um passo atrás na minha busca pelos aspectos universais das narrativas, analisando, antes, a universalidade na forma musical do gênero musical em questão. Porém, o que uma forma musical tão regional e brasileira poderia ter de universal?

A resposta esta pergunta é, de certa forma, essencialmente sociológica e remete às reflexões de Lévi-Strauss (1982) sobre aquilo que existe em toda sociedade indo desde a mais tribal ou "simples" até a mais complexa. Todas elas, segundo o autor, têm algo que thes é comum: o tabu do incesto. Obviamente que as regras que definem o que é incesto $e$, consequentemente, definem com quem se pode casar ou não variam de sociedade para sociedade. Mas, todas sempre possuem uma regra para este assunto.

Analogamente a este pensamento, pode-se dizer que todo gênero musical têm algo que thes é comum: as convenções ou regras de composição. E a exemplo do ocorre com o tabu do incesto, cada gênero musical tem suas próprias convenções e regras que os compositores aprendem (de modo formal ou informal) e que devem minimamente seguir para que suas composições tenham legitimidade junto ao seu público. De modo semelhante, a moda-de-viola também possuía suas

\section{8}


convenções ligando-se, desta forma, a este aspecto que é universal na música.

Quais eram, no entanto, estas convenções das modas-de-viola? Eis o que me dispus a responder na primeira parte da minha pesquisa para então, sob esta base musical, tratar das narrativas que eram meu interesse inicial. Este segundo objetivo, no entanto, foi realizado? Como se verá aqui, não foi. Ao menos, não necessariamente na proporção que eu havia planejado porque, como dizia uma música da dupla Tião Carreiro e Pardinho: "uma coisa puxa outra" e os assuntos são sempre mais complexos do que imagina "nossa vã filosofia".

\section{Régua, prumo e nível}

Em novembro de 2015, isto é, quatro meses após a apresentação do meu projeto de pesquisa no Kings College, eu tive a primeira oportunidade de apresentar os resultados parciais da minha pesquisa em andamento num congresso realizada na Inglaterra e organizado pelo Institute of Latin American Studies e Institute of Musical Research of the 'School for Advanced Study' da University of London. Trata-se do Latin American Music Seminar, o qual é realizado anualmente.

título da minha apresentação, neste evento, foi Rules of Composition for the moda-de-viola: a rural Brazilian song-form. Como se vê, o título em si já refletia as alterações decorrentes das sugestões que eu havia recebido do grupo de pesquisadores do Kings e que apontavam para a relevância do estudo das regras de composição da moda-deviola como elemento que a conectava à universalidade dos gêneros musicais. E foi justamente a explicação deste novo enfoque da minha pesquisa em relação ao seu propósito inicial que correspondeu ao primeiro ponto da minha apresentação.

Em seguida a esta introdução, eu apresentei também as justificativas do estudo das regras de composição da moda-de-viola: em primeiro lugar, por haver muitas questões ainda não respondidas sobre este tema; e, em segundo lugar porque, quando estudamos as convenções utilizadas pelos compositores, estamos também estudando o que dava legitimidade a este gênero musical e que, portanto, dava base musical para quaisquer outras construções hegemônicas que viessem a

\section{9}


ser elaboradas por suas narrativas como, por exemplo, aquelas que eu havia estudado no meu doutorado.

Uma dessas construções hegemônicas, por assim dizer, correspondia a um esforço por integrar o espírito da nova ordem econômica à uma ética pautada essencialmente em valores pretensamente tradicionais como era a da sociedade caipira. Um processo nem sempre claro e unilateral, mas que, segundo Weber (2001), é fundamentalmente necessário para o desenvolvimento do capitalismo. A decodificação desta construção hegemônica foi, inclusive, o tema da minha tese de doutorado. Porém, na minha apresentação no congresso em questão, eu evitei me aprofundar nesta exposição para manter o foco naquilo que eu pretendia apresentar em seguida: as regras de composição da moda-de-viola, as quais eu pude, inclusive, ilustrar com a citação do trecho da moda Padecimento que foi gravada pela dupla Tião Carreiro e Pardinho.

Nesta moda, como se pode ver a seguir, vê-se claramente como que o aprendizado dessas convenções formais era de conhecimento dos compositores e intérpretes que a aprendiam no modelo tradicional de ensino mestre-aprendiz. No trecho a seguir, o intérprete nos conta o método que ele utilizou para se tornar um bom compositor: ele o aprendeu com um violeiro antigo que já era versado nesta arte. Porém, não se trata apenas de copiar o estilo: o compositor tem consciência dos diferentes elementos que ele lança mão para compor suas modas, o que é apresentado na forma de analogia com instrumentos de construção civil que, diga-se de passagem, era normalmente a ocupação profissional que esperava os migrantes que migravam do campo para a cidade na época (DURHAM, 1973).

Pra aprender cantar de viola, primeiro estudo que eu tive Aprendi com um violeiro véio, que fazia moda impossíve Pois eu sou um violeiro novo, mas também quero ser terrive Faço moda de gente boa e de algum incorrigive Toda moda que eu invento ocupo régua, prumo e níve (Ai) pensando bem um violeiro com prazer no mundo vive (ai, ai, ai $)^{1}$.

I Nesta transcrição, procurei manter a pronúncia original dos intérpretes, não corrigindo o português. 
Este trecho desta moda-de-viola, de certa forma, veio a facilitar minha exposição para o público inglês, uma vez que não era necessário traduzir termos e técnicas musicais específicas do toque da viola caipira. Em vez disso, eu precisei apenas traduzir os instrumentos que eram utilizados na construção civil, aos quais o compositor se referia como expressão da consciência que tinha das convenções utilizadas na elaboração de uma música: régua, plumo e nível que, em inglês, ficou como ruler, lever and plum line.

Em seguida à esta introdução, minha apresentação se ocupou com a exposição dos elementos estruturais presentes na moda-de-viola. E embora eu tivesse considerado a análise de diferentes autores que pensaram de forma razoavelmente sistemática sobre o assunto como Mário de Andrade, Amadeu Amaral, Rossini Tavares de Lima, Alceu Maynard Araújo, José Carlos Zamboni e Maria Madalena Bernadeli, dentre outros quase cinquenta trabalhos que consultei, devido ao tempo restrito da apresentação, eu optei por apresentar apenas dois autores: Mário de Andrade e Rafael Marin da Silva Garcia.

A escolha por Mário de Andrade se deu porque, apesar da sua reflexão ser possivelmente a mais antiga de todas, os elementos que ele observou na forma musical da moda-de-viola foram retomados pela maioria dos autores que vieram depois dele. Quanto a Rafael Marin, sua escolha se deu porque ele foi o único autor a escrever um trabalho de envergadura (uma dissertação de mestrado) voltado especificamente para a análise da forma musical ou para os elementos estruturais presentes neste gênero musical². Além disso, Rafael fez uma divisão, entre os elementos estruturais constitutivos de uma moda-de-viola, que me pareceu muito pedagógica sendo por isso também adotada por mim.

Na sua dissertação de mestrado, Rafael Marin chamou de partes fixas aqueles elementos que fazem parte da forma musical de uma moda-de-viola e que necessariamente estão presentes em toda composição deste gênero musical; e chamou de partes móveis aqueles elementos que aparecem em apenas algumas dessas composições acrescidos, portanto, dos elementos obrigatórios. Na minha exposição, no entanto, eu chamei as partes fixas de elementos essenciais de uma moda de viola; e às partes móveis, eu chamei de elementos opcionais. Em seguida, eu

2 Apesar de Eduardo de Almeida Menezes (2008), ter apresentação uma dissertação de mestrado dedicada também à moda-de-viola três anos antes que a dissertação de Rafael Marin, este trabalho de Menezes esteve mais restrito à análise das letras não chegando, portanto, a fazer uma reflexão sistemática sobre a forma musical da moda-de-viola.

\section{1}


montei dois esquemas gráficos para melhor ilustrar este modelo estrutural para o público presente no Latin American Music Seminar e que serão apresentados nas duas figuras a seguir.

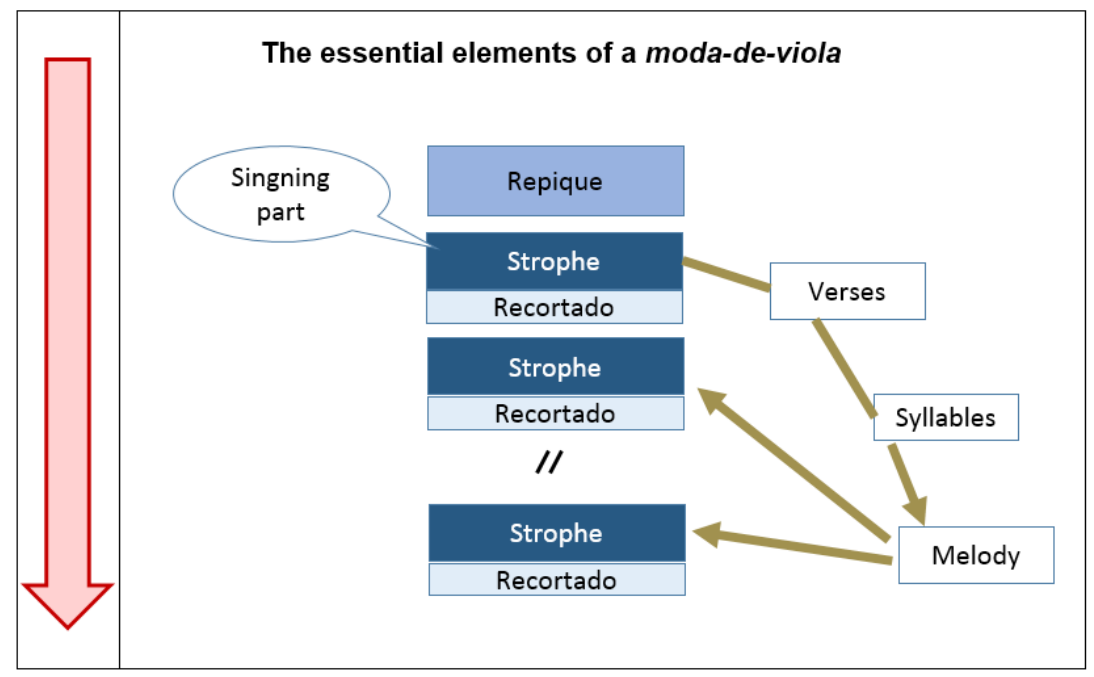

Figura 1: elementos obrigatórios das modas-de-viola

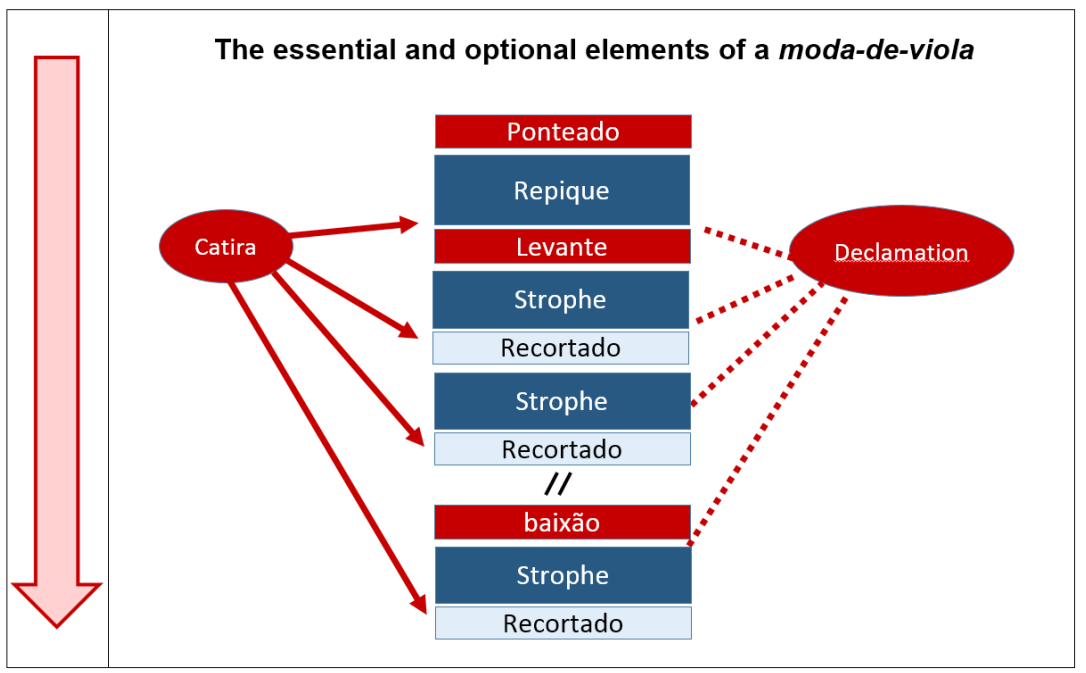

Figura 2: elementos obrigatórios e opcionais das modas-de-viola 
Após o referido congresso, esses esquemas gráficos das figuras 1 e 2 foram revisados com base em comentários recebidos posteriormente. E uma dessas revisões diz respeito à inclusão da seta do lado esquerdo que indica o sentido de leitura da figura $e$, consequentemente, da ordem do surgimento dos elementos na música. Com base nisso, pode-se aqui proceder a uma leitura análoga à exposição que fiz:

- Figura 1: mostra que os elementos essenciais de moda-deviola são compostos pelo repique, recortado e as estrofes. As estrofes correspondem à parte cantada, enquanto que o repique e o recortado são as partes instrumentais. $\bigcirc$ repique é a primeira coisa que se ouve numa moda-de-viola e corresponde a uma espécie de introdução instrumental que pode ser mesmo muito breve. Em seguida a ele vêm a primeira estrofe que é composta por um desenho melódico, de versos e de silabas que devem se manter os mesmos ao longo de todas as estrofes. Essas estrofes são sempre seguidas por uma parte instrumental chamada recortado ao qual, por sua vez, é seguido por uma nova estrofe que é então seguida novamente por um recortado e assim até o final da moda;

- Figura 2: mostra todos os elementos estruturais de uma moda de viola com destaque, no entanto, para os elementos opcionais que são: ponteado, levante, baixão, catira e declamação. $O$ ponteado e a catira são partes instrumentais, enquanto que o levante e o baixão são as partes cantadas. E a declamação? Esta não é nem uma coisa nem outra. Trata-se apenas de uma declamação como quem declama uma poesia. E as linhas pontilhadas que a ligam ao corpo central da estrutura sugerem que ela pode aparecer em diferentes momentos da música. Já a linha contínua da catira indica que, uma vez presente numa moda-de-viola, este ritmo que corresponde à uma dança tradicional da cultura caipira, deve se repetir entre as estrofes da moda. Já as posições do ponteado, do levante e do baixão são relativamente fixas e únicas, no sentido de aparecer uma única vez: o ponteado aparece na introdução instrumental, o levante antes da primeira estrofe e o baixão antes da última estrofe lembrando que levante e baixão são pequenas estrofes cantadas.

\section{3}


Minha participação no congresso já estava terminando quando, nos minutos finais da sessão de questões e respostas, um dos pesquisadores ali presentes perguntou-me quais teriam sido os músicos e compositores que teriam rompido com este modelo estrutural que eu ali apresentava.

A pergunta era interessantíssima porque relembrava que se as convenções nas composições musicais são um aspecto universal, a quebra dessas convenções também faz parte desta dinâmica. $\bigcirc$ problema é que para responder a esta pergunta razoavelmente curta seria preciso repassar toda a história da moda-de-viola confrontando cada dupla de intérpretes ou compositores a este modelo geral para ver quando ele foi quebrado e de que forma o foi. Eu poderia ter deixado este trabalho complementar de pesquisa "para a posteridade", por assim dizer. Porém, achei que eu precisava dizer algo mais sobre o assunto diante do risco desta reflexão não ser mais retomada por outro pesquisador. Por isso, nos meses seguintes, eu me dediquei a uma pesquisa empírica com este fim, cujos resultados serão tratados no próximo tópico.

\section{Transformações e revisões}

Nos seis meses que se seguiram à primeira apresentação no Latin American Music Seminar, eu me dediquei a duas diferentes vertentes de análise: àquela que dizia respeito à forma musical da moda-de-viola; e à busca pelos aspectos universais a partir de análise das letras das modas. A primeira dessas vertentes correspondia à continuidade da pesquisa que eu havia feito no semestre anterior, enquanto que a segunda representava uma tentativa de retomar o projeto inicial. Mas, apesar de eu ter escrito um artigo sobre esta segunda vertente, as duas oportunidades de apresentação em congressos internacionais não me permitiram apresentar estes resultados.

Em junho de 2016, ou seja, no final do meu período como pesquisador visitante no Kings, eu fui aceito para participar de um congresso realizado na cidade de New Castle, localizada no norte da Inglaterra. Neste congresso, organizado pelo Postgraduates in Latin American Studies (PILAS), e que recebeu o nome de Latin America in Transformation: Bridging disciplinary boundaries, eu realizei uma apresentação com o titulo Moda-de-viola and the transformation of the Brazilian Society in the Twentieth Century.

\section{4}

REV. TULHA, RIBEIRÃO PRETO, v. 2, n. 2, p. 154-176, jul.-dez. 2016 
Para criar uma aderência da minha pesquisa do Kings com o tema do evento, eu acabei incluindo a apresentação de parte dos resultados da minha pesquisa de doutorado na qual eu havia estudado justamente as transformações pelas quais passaram a sociedade brasileira e que foram, por mim, analisadas a partir das letras das modasde-viola. Assim, eu dividi minha apresentação em três tópicos: o que eu pesquisei no doutorado; o que pesquisei no Kings College; e o que pretendia continuar estudando após a conclusão deste período no Kings.

Em relação ao primeiro desses tópicos, eu falei sobre como o estudo das letras das modas-de-viola, que fiz no doutorado, é capaz de revelar uma "outra história" ou "uma história vista debaixo" (BENJAMIN, 1994, p. 225) do êxodo rural que se acelerou em meados do século XX mudando o cenário demográfico do Brasil no espaço de poucas décadas. Neste sentido, expliquei um dos principais motivos que levou à escolha das modas da dupla Tião Carreiro e Pardinho como recorte de pesquisa: o fato de sua longa carreira coincidir com o período histórico em que se processou a grande mudança demográfica sendo, por isso, adequada para se compreender os potenciais dilemas e tensões deste processo de adaptação cultural do camponês paulista.

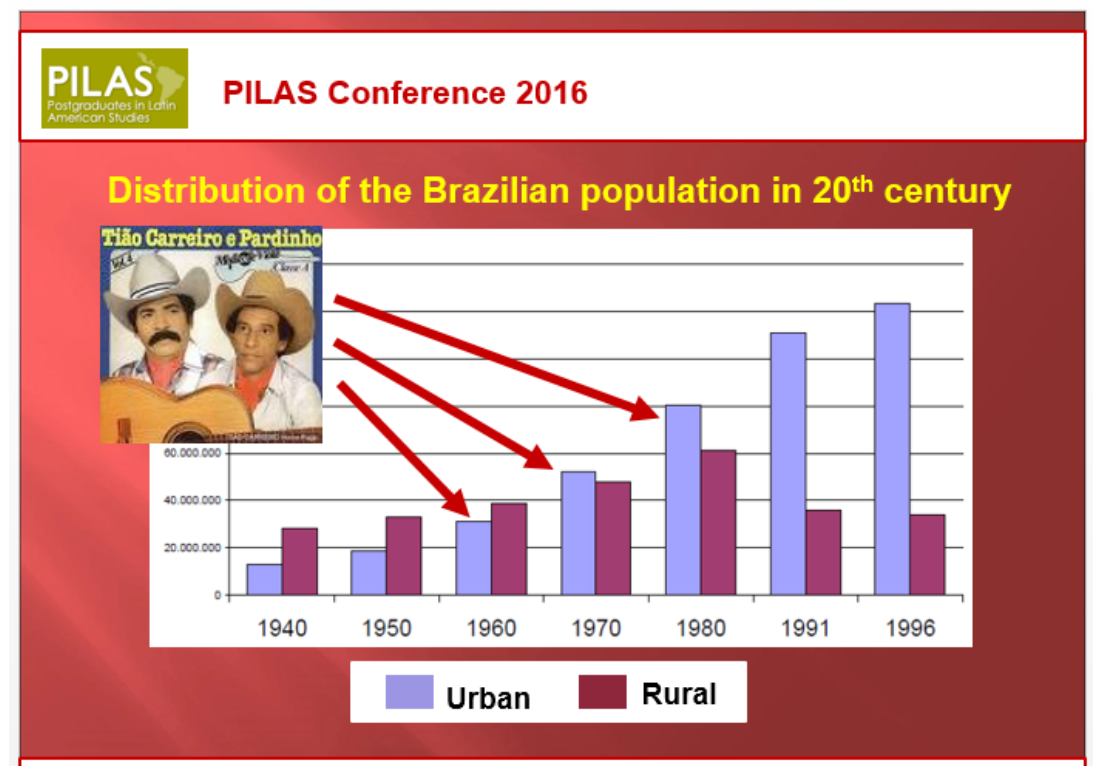

Figura 3: distribuição demográfica da população brasileira 
Em seguida, no segundo tópico da apresentação, eu falei sobre minha pesquisa no Kings e como ela nasceu do desejo de revisitar este mesmo objeto de pesquisa (as modas-de-viola gravadas pela dupla Tião Carreiro e Pardinho) em busca de algo complementar à compreensão do seu aspecto regional que eu havia estudado no meu doutorado, ou seja, de seus aspectos universais.

Neste sentido, após destacar a diferença do plano inicial (a análise das letras) do que foi efetivamente realizado (a análise da forma musical), eu apresentei o modelo estrutural da moda-de-viola com os elementos obrigatórios e com os elementos opcionais que já foram aqui tratados nas figuras 1 e 2. A diferença, porém, foi que desta vez eu cantei e toquei uma dessas modas ao vivo ilustrando também visualmente os elementos básicos que necessariamente se fazem presentes em toda composição do gênero musical.

E neste ponto reside um dos resultados da revisão que fiz no modelo geral aqui já apresentado. Na versão anterior do modelo, que elaborei com base na leitura do mestrado de Rafael Marin e na sua contraposição com as análises de outros autores, eu havia identificado três elementos obrigatórios em toda moda-de-viola: um cantado (as estrofes) e dois instrumentais (o repique e o recortado). Contudo, numa nova leitura que fiz da dissertação de mestrado de Rafael Marin, ao consultar uma nota de rodapé do texto, notei que repique e recortado eram utilizados como sinônimos. Por isso, nesta revisão que fiz do modelo estrutural da moda-de-viola e que apresentei neste congresso, eu suprimi o nome repique chamando-o, nesta introdução, também de recortado.

Outra alteração feita neste modelo diz respeito à posição do ponteado. No modelo anterior, eu havia indicado seu aparecimento previamente ao recortado. Porém, depois de averiguar melhor, cheguei à conclusão de que o ponteado pode vir tanto antes quanto depois do recortado. Em consequência disto, alterei sua representação gráfica deixando-os um ao lado do outro como pode ser visto na figura a seguir que consolida estas duas alterações no modelo.

A moda que eu cantei e toquei foi Catimbau. Ela foi gravada pela dupla Tião Carreiro e Pardinho fazendo, por este motivo, parte do objeto de pesquisa do meu doutorado e também da pesquisa no Kings. Nesta moda, a introdução instrumental (o recortado) é igual ao

\section{6}


que é tocado entre as estrofes e dura poucos segundos. E as estrofes são compostas sempre por seis linhas, cuja rima é formada sempre com base na última silaba poética de cada frase constituída por dezesseis silabas.

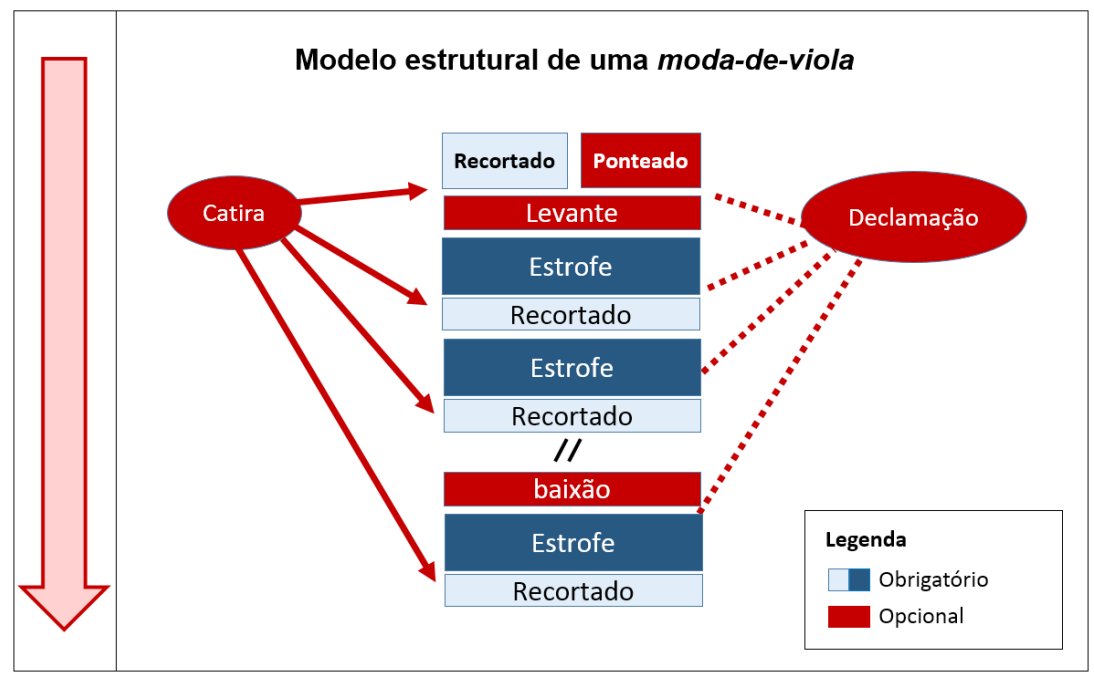

Figura 4: modelo estrutural revisado da moda-de-viola

E para ajudar na compreensão do que a letra dizia, eu utilizei-me de uma tradução literal apresentando, em inglês, a trágica história de amor de Rosinha e Catimbau - ou, para ser mais específico: somente as duas primeiras estrofes (de um total de seis), devido à limitação do tempo. A interpretação das duas estrofes foi, no entanto, suficiente tanto para ilustrar os elementos obrigatórios de uma moda-de-viola quanto para mostrar como a mesma melodia se repetia a cada estrofe.

No final de minha interpretação, eu toquei o áudio da gravação original da moda Catimbau cantada e tocada por Tião Carreiro e Pardinho para destacar não só a diferença de interpretação como também o fato de uma moda ser sempre cantada em dupla diferentemente, portanto, do que eu havia acabado de fazer pelas limitações óbvias de não ter um parceiro. Além disso, eu mencionei os outros elementos opcionais de uma moda-de-viola a partir da exposição do modelo estrutural revisado da moda-de-viola (figura 4). 
Chegando, então, ao terceiro e último ponto de minha apresentação, eu destaquei os novos horizontes que agora se abririam para novas pesquisas decorrentes das questões que haviam sido levantadas durante minha pesquisa. A saber:

- a continuidade da pesquisa sobre a forma musical da modade-viola, tanto pelo caminho da análise comparada do que foi gravado com o modelo estrutural que eu havia apresentado quanto pela perspectiva do aprofundamento de análise em aspectos que eu não havia trabalhado ainda como, por exemplo, a recorrência de desenhos melódicos do canto ou dos desenhos rítmicos da parte instrumental podendo ainda estender isto para uma possivel recorrência de acordes ou intervalos musicais;

- a elaboração de uma história geral da moda-de-viola no século XX, com ênfase não só nos nomes dos principais intérpretes e compositores, mas com base nas inovações e rupturas em relação ao modelo estrutural que eu apresentei aqui;

- ou ainda uma retomada da análise das letras dessas modasde-viola para procurar, em suas narrativas, os aspectos universais que ligam os dilemas e valores morais de seus personagens aqueles disseminados e desenvolvidos pela literatura em geral.

Concluida minha apresentação, fiquei surpreso com uma das intervenções feitas por um pesquisador do grupo que traçou um paralelo entre a moda-de-viola e o rap enquanto duas expressões musicais que têm em comum a elaboração de narrativas que tratam dos dilemas vividos por uma população ligada à periferia das cidades. Esta observação, vinda de um pesquisador que não era brasileiro e nem tampouco especialista na cultura brasileira, me deixou surpreso porque ecoou uma declaração análogo que eu havia ouvido alguns meses atrás de um rapper brasileiro que contou, numa entrevista à $T^{3}$, que seu pai gostava das músicas de Tião Carreiro e Pardinho e que ele, quando criança, admirava o gosto do pai por aquelas narrativas e compreendia, agora, que as narrativas de suas músicas seguiam esta mesma tradição ainda que em contextos e tempos diferentes.

3 Entrevista disponivel em http://ashow.globo.com/programas/esquenta/episodio/20 15/07/12/esquenta-recebe-chitaozinho-e-xororo-projota-e-mais-uma-disputa-do -esquentanejo.html\#video-4316558

\section{8}


E após o encerramento da sessão, eu fui também surpreendido por um pesquisador chileno que pediu para conhecer de perto a viola caipira que eu havia levado afirmando que ela lembrava um instrumento da cultura popular chilena: o guitarrón $n^{4}$. E, para minha surpresa, alguns minutos depois, ele já tinha conseguido tocar uma música na minha viola com a afinação cebolão. Eis, portanto, uma interessante dica de pesquisa para um estudo musicológico futuro.

\section{Da mediação à diáspora}

No mesmo mês do congresso do PILAS em New Castle, houve um simpósio em Londres promovido pelo próprio Kings College que coincidiu com a conclusão das minhas atividades na condição de pesquisador visitante daquela instituição. Neste congresso, que recebeu o título de City to City: urban crossroads in the music of Africa, Brazil and Portugal, eu coordenei a sessão Migrations and diasporas na qual também fiz a apresentação: Diaspora in the moda-de-viola. E apesar da estrutura desta apresentação ter sido semelhante àquela que fiz em New Castle, seu escopo foi diferente em decorrência do tema sugerido pela sessão a que ela pertencia: Migration and Diaspora.

No início da apresentação, eu tratei da intrínseca ligação que a moda-de-viola tem com o tema migrações. Uma ligação que, digase de passagem, se estende também à música caipira a qual ela se integra. De fato, eu já havia tido a oportunidade de discorrer sobre esta ligação no Second Forum of Sociology for the International Sociology Association (ISA) em 2012, numa apresentação intitulada Inside Migration: the countryman's integration through the caipira music, que na época coincidiu com algumas reflexões que eu estava fazendo no contexto da minha tese de doutorado.

Essas reflexões, a propósito, correspondiam ao centro da minha hipótese de pesquisa: a de que era possível reconstituir a história do êxodo da população camponesas paulista para as cidades, através do estudo do registro que foi deixado nas narrativas das modas-de-viola.

$4 \bigcirc$ mesmo pesquisador, Ignácio Rivera Volosky, me enviou um link de um vídeo na internet onde aparece um músico tocando este instrumento e afirmando que ele é próprio da cultura camponesa chilena: https://www.youtube.com/watch? $v=O w h h C E O a N X 8$

\section{9}


Porém, passados quatro anos após este congresso do ISA e concluída minha pesquisa de doutorado, posso afirmar que esta hipótese não somente mostrou-se válida como também serviu para destacar que as narrativas das modas-de-viola são mais do que uma fonte documental de reconstituição histórica. Mais que isso, elas foram também um instrumento de mediação com a realidade e, consequentemente, de solução alternativa para os conflitos surgidos em decorrência do êxodo forçado do camponês para a cidade.

Em seguida, eu tratei também da forma musical da moda-de-viola - uma vez que este havia sido o tema da minha pesquisa no Kings e a participação neste evento exigia também que eu apresentasse esses resultados. Inicialmente, minha exposição foi semelhante àquela que eu havia feito no congresso de New Castle, inclusive, cantando e tocando a moda Catimbau para ilustrar os principais elementos estruturais obrigatórios em toda composição do gênero.

Após esta interpretação, eu também expus os resultados do último semestre da minha pesquisa sobre o tema. Resultados que foram apresentados em detalhes no artigo A Série Cornélio Pires: análise da forma musical das suas modas-de-viola, o qual escrevi em parceria com Rafael Marin e que foi aceito pela revista Debates da UNIRIO na mesma semana em que eu estava participando deste congresso no Kings. Este artigo surgiu como desdobramento da apresentação que eu fiz no Latin American Music Seminar quando ao seu final, um dos pesquisadores havia me questionado sobre quais teriam sido os músicos e compositores que teriam rompido com aquele modelo estrutural da moda-de-viola que eu havia apresentado.

Assim, em resposta a esta provocação científica, por assim dizer, eu comecei a realizar tal análise a partir do início da história da moda-de-viola na indústria dos discos: nos primeiros discos gravados em 1929- 1930 sob o selo Cornélio Pires. A confrontação dessas 30 modas com o modelo estrutural da moda-de-viola que eu havia apresentado em Londres, em novembro do ano anterior, mostrou que $80 \%$ dessas modas adequavam-se ao modelo. Quanto àquelas 6 modas que apresentavam rupturas com o modelo, isto aconteceu pelos seguintes motivos: alteração na melodia das estrofes ( 1 moda), uso de repetição de frases no estilo refrão (2 modas), repetição de estrofes (3 modas) e uso de mais de um levante (2 modas).

\section{0}


E ao final desses quatro aspectos, eu ressaltei também um que não havia sido mencionado anteriormente e que diz respeito à participação de uma voz feminina na interpretação de algumas dessas modas-de-viola. Isto é surpreendente porque embora existam cantoras relativamente famosas na música caipira em geral, o mesmo não acontece com o gênero moda-de-viola sendo este, inclusive, um dos aspectos que surpreendem na revisitação que Ivan Vilela, juntamente com Lenine Santos e Suzana Salles, fazem de algumas modas-de-viola tradicionais no CD Caipira lançado em 2004. Nesta nova interpretação, as rupturas com a forma musical do gênero são evidentes, assim como parece ser também, esta, a intenção dos músicos. E para mostrar esta ruptura, eu toquei um trecho da gravação original que a dupla Tião Carreiro e Pardinho fez da moda Ingrata tocando, em seguida, o áudio da versão cantada por Suzana Salles.

Em seguida, dei início à última parte da minha apresentação destacando, como eu já havia feito no Congresso de New Castle, os novos horizontes de pesquisa surgidos durante minhas análises acrescentando, entretanto, uma última possibilidade àquelas já mencionadas no item anterior deste artigo: o estudo da diáspora de violeiros brasileiros e, consequentemente, da viola caipira.

E embora não se trata aqui propriamente de uma diáspora no sentido próprio de palavra, ainda assim trata-se de um tipo de deslocamento interessante que notei ao longo da minha pesquisa. Refiro-me às apresentações que alguns violeiros brasileiros têm feito não somente na Europa em geral como também para a cidade de Londres por onde já passaram os violeiros e pesquisadores Ivan Vilela e João Paulo Amaral e, recentemente, o violeiro e professor de viola caipira Almir Pessoa que em janeiro de 2017 deverá ministrar o primeiro curso de viola caipira na World Heart Beat Music Academy. E isto sem contar o violeiro Renato Velasco que reside em Paris, onde também dá aula de viola caipira. Trata-se, portanto, de um fato cultural curioso que mereceria atenção de uma pesquisa específica dadas as possibilidades musicais que podem surgir desta troca cultural.

E coincidentemente, na mesma semana do referido congresso do Kings, o violeiro Almir Pessoa estava em Londres - razão pela qual convidei-o a fazer uma intervenção musical ao final da minha apresentação. Uma intervenção que, por ter sido combinada apenas com o coordenador do evento, causou certo efeito surpresa positivo no público

\section{1}


ali presente que pode, assim, ver e ouvir de perto um violeiro profissional interpretando uma música caipira. Atendendo a um pedido meu, Almir tocou a música A Viola e o Violeiro que faz parte da série de discos Modas de Viola Classe A de Tião Carreiro e Pardinho sendo, a propósito, a única música a integrar esta série e que não é uma moda-de-viola.

\section{Considerações Finais}

A falta de aderência de algumas modas-de-viola da série Cornélio Pires ao modelo estrutural, aqui proposto, não invalida o mesmo porque, como foi visto no tópico anterior, as rupturas observadas não diziam respeito a nenhum dos elementos estruturais com exceção de um duplo levante observado em duas modas. Porém, como isto aconteceu em apenas duas dentre um total de trinta analisadas, prefiro considerar o fato como uma exceção - fruto, ao que parece, de um descuido ou mesmo falta de domínio da forma musical da moda-de-viola naqueles primeiros anos da música caipira na indústria do disco.

Mas, claro que, numa perspectiva de longo prazo, esta é uma afirmação de caráter temporário que pode ser comprovada ou negada somente através de uma revisão histórica das modas-de-viola gravadas no século XX. E é por isto que, a meu ver, a perspectiva de uma história geral da moda-de-viola me parece muito interessante: não somente para validar o modelo estrutural como também para revelar as mudanças que podem ter ocorrido ao longo do tempo.

No entanto, esta história geral da moda-de-viola (ou a revisão da história atualmente disponível) não precisa e nem deveria ser pautada somente pela análise da forma musical porque, embora este seja um ponto fundamental cuja aparente constância ajudou a manter o apreço deste gênero musical junto ao público ouvinte, há também que se considerar aquele elemento sem o qual uma moda-de-viola perde sua razão de ser: suas narrativas.

Assim, é essencial que uma história geral da moda-de-viola considere não somente a forma musical como também o conteúdo de suas narrativas além, obviamente, de outros elementos não mapeados aqui e que possam contribuir para uma melhor compreensão deste gênero musical que teve um lugar de destaque na música caipira e no imaginário

\section{2}


de toda uma geração que a tomou como uma das referências para se pensar num novo sentido e significado para suas vidas em meio a um mundo em transformação.

E se desta revisão histórica de um gênero musical tão regional surgir algo que é universal, não haverá de se surpreender o pesquisador que sabe que, nos rios e lagos dos mais remotos e pequenos vilarejos, sempre se pode ver o reflexo da mesma lua.

\section{Referências Bibliográficas}

ALMAN, Taizi Caroline e Silva. O Poema narrativo na canção caipira. 1990. 137p. Dissertação (Mestrado em Letras) - Programa de Pósgraduação em Letras, Universidade Federal de Mato Grosso do Sul, Três Lagoas, 1990.

ALVES, Emiliano Rivello. Cornélio Pires e Monteiro Lobato: da esperança à melancolia - o debate sobre o progresso. 2012. 303p. (Tese em Sociologia) - Departamento de Sociologia, Universidade de Brasília, Brasilia, 2012.

AMARAL, Amadeu. Tradições populares. São Paulo: Instituto Progresso, 1948.

ANDRADE, Mário de. Dicionário musical brasileiro. Brasilia, Belo Horizonte: Ministério da Cultura: Itatiaia, 1989.

ARAÚJO, Alceu Maynard. Cultura popular brasileira. $2^{\natural}$ edição. São Paulo: Melhoramentos, 1973.

ARAÚJO, Alceu Maynard. Folclore nacional I: festas, bailados, mitos e lendas. 3". edição. São Paulo: Martins Fontes. São Paulo, 2004.

ARAÚJO, Alceu Maynard. Folclore nacional Il: danças, recreação, música. São Paulo: Melhoramentos, 1964.

ARAÚJO, Alceu Maynard. Folclore nacional III: ritos, sabença, linguagem, artes e técnicas. São Paulo: Melhoramentos, 1964.

BASTIDE, Roger. $O$ folclore paulista. Cadernos. Centro de Estudos Rurais e Urbanos, São Paulo, n. 10, p.63-65, nov. 1977.

\section{3}


BENJAMIN, Walter. Magia e técnica, arte e politica: ensaios sobre literatura e historia da cultura. Tradução Sergio Paulo Rovanet. I ed. São Paulo: Brasiliense, 1994 (Obras Escolhidas; v. 1).

BENJAMIN, Walter. Rua de mão única. Tradução Rubens Rodrigues Torres Filho e José Carlos Martins Barbosa. São Paulo: Brasiliense, 1987 (Obras Escolhidas; v.2)

BERNADELL, Maria Madalena. A expressividade caipira em Vieira e Vieirinha. 1991. 217p. Dissertação (Mestrado em Letras) - Curso de Pós-graduação em letras, Universidade Estadual Paulista, São José do Rio Preto, 1991.

CANDIDO, Antonio. Literatura e sociedade. 8. ed. São Paulo: Plubifolha, 2000.

CORRÊA, Roberto. Os Primordios dos Discos Comerciais da Música Tradicional Brasileira. Revista Novos Olhares. Vol. 1, nº 2, p. 84-89.

DENT, Alex Sebastian. Country Critics: Música Caipira and the Production of Locality in Brazil. Dissertation (Doctor of Philosophy) - Departament of Anthropology. University of Chicago, 2003.

DENT, Alex Sebastian. River of Tears: Country Music, Memory, and Modernity in Brazil. Durham: Duke University Press, 2009.

DURHAN, Eunice. A caminho da cidade: a vida rural e a migração para São Paulo. São Paulo: Perspectiva, 1973.

FAUSTINO, J. C.; GARCIA, R. M. S. A Série Cornélio Pires: analise da forma musical das suas modas-de-viola. DEBATES - Cadernos do Programa de Pós-Graduação em Música, v. 16, p.63 - 89, 2016.

FAUSTINO, J. C. A Modernidade Sincopada: moda de viola e o exodo rural no Brasil. Brasiliana, v.4, p. 128 - 158, 2015.

FAUSTINO, Jean Carlo. A moda de viola enquanto literatura: a quintessência da sabedoria caipira. In: Souza, Marly Gondim Cavalcanti; Silva, Agnaldo Rodrigues da (org.) Diálogo entre literatura e outras artes. Cáceres, MT: Ed. UNEMAT, 2014. p. 121-136.

FAUSTINO, J. C. As contribuições do romance de formação na moda de viola para compreensão do exodo rural. Revista Ecos, v.16, p.93 - 105, 2014.

\section{4}


FAUSTINO, Jean Carlo. O Exodo Cantado: a formação do caipira para a modernidade. 2014 . 196p. Tese (Doutorado em Sociologia) Curso de pós-graduação em Sociologia, Universidade Federal de São Carlos, São Carlos, 2014.

FAUSTINO, Jean Carlo. Des troupeaux invisibles. L'imaginaire du caipira dans la grande ville. Caravelle, n. 99, 2012, p. 195-213. http:// caravelle.revues.org/427

FAUSTINO, J. C. Entre a Formação e a Desilusão: literatura e sociedade na moda de viola. Revista Ecos, v.15, p.108 - 123, 2013.

FAUSTINO, J. C. Perdas Invisiveis: a música caipira e o exodo rural brasileiro. Sociopoética (Online), v.11, p.53 - 67, 2013.

FAUSTINO, J. C. O romance de formação (bildungsroman) na moda de viola: literatura e sociedade na música caipira. Revista Ecos, v. 12 , p.21 - 39, 2012.

FAUSTINO, J. C. A moda de viola enquanto literatura In: Souza, Marly Gondim Cavalcanti; Silva, Agnaldo Rodrigues da (org.). Escritos culturais: literatura, arte e movimento. Cáceres, MT: UNEMAT, 2011, v.1. p.274. ISBN: 9788579110672

FAUSTINO, J. C. O Caipira, o boi e a viola: representação e superação simbólica do caipira diante do exxodo rural em São Paulo. Cadernos Ceru (USP). , v.20, p.115 - 131, 2009.

FAUSTINO, J. C. O êxodo cantado: A música tradicional paulista como fonte para uma historia oral. Oralidades (USP), v. I, p.l - 50, 2007.

FAUSTINO, J. C. Rosinha e Catimbau: análise de um processo de transformação social através da música caipira. História Social (UNICAMP), v.13, p.221 - 239, 2007.

GARCIA, Rafael Marin da Silva. Moda-de-viola: lirismo, circunstancia e musicalidade no canto recitativo caipira. 2011.335p. Dissertação (Mestrado em Música) - Instituto de Artes. Universidade Estadual Paulista, São Paulo, 2011.

LÉVI-STRAUSS, Claude. As Estruturas elementares do parentesco. Tradução de Mariano Ferreira. Petrópolis, Vozes, 1982.

LIMA, Rossini Tavares de. Moda de viola: poesia de circunstância. São Paulo: Secretaria do Estado da Cultura, 1997.

\section{5}


SANT'ANNA, Romildo. A moda é viola: ensaio do cantar caipira. São Paulo: Arte \& Ciência; Marilia, SP: Ed. UNIMAR, 2000.

VILELA, Ivan. O caipira e a viola brasileira. In: PAIS, José Machado; BRITO, Joaquim Pais de; CARVALHO, Mário Vieira de (orgs.). Sonoridades Iuso-afro-brasileiras. Cap. X. Lisboa: Imprensa de Ciências Sociais, 2004, p. $171-187$.

ZAMBONI, José Carlos. O cantador do Rio Bonito: estudo sobre a poesia caipira. 1987. 225p. Dissertação (Mestrado em Letras) - Faculdade de Ciências e Letras. Universidade Estadual Paulista, Assis, 1987.

UEBER, Max. A ética protestante e o espírito do capitalismo. Tradução: Pietro Nassetti. São Paulo: Martin Claret, 2001.

UEBER, Max. Sociologia. Organizador: Gabriel Cohn. Coordenador: Florestan Fernandes. $7^{\circ}$. Edição. Editora Ática. São Paulo.

\section{Sobre o autor}

Jean Carlo Faustino é doutor em Sociologia pela Universidade Federal de São Carlos (UFSCar) e mestre, também em sociologia, pela Universidade Estadual de Campinas (UNICAMP). De abril de 2015 a junho de 2016 foi pesquisador visitante associado no Departamento de Estudos Latino-americanos, Espanhóis e Portugueses da Faculdade de Artes e Humanidades do King's College de Londres.

Recebido em: 28/09/2016

Aprovado em: 28/03/2017 